\title{
A CASE OF HYSTERO-EPILEPSY IN THE MALE.
}

BY JAMES-OLIVER; M.B. (EDLN.), M.R.C.P. (LOND.),

Medical Registrar to the National Hospitul for Paralysed and Epileptic.

HYSTERo-EPILEPSY in the well-marked form is, comparatively speaking, rarely seen in this country, either in the male or female, but more especially in the male; in either sex, however, the symptoms may be identical. It is possible, nay likely, that as our knowledge of this disease extends, we shall admit into this category cases which even in the male we previously in our ignorance passed unheeded, or classed far otherwise. Hitherto the phenomena of hysteria have been usually associated with the female habit of body, and we have spurned the notion that the active, well-developed labourer could, whilst in apparently good health, become the victim of this affection. Hysteria is a word which as at present employed is quite unintelligible. It is employed too indiscriminately, and more or less as a "cloak." In the male the symptoms are, as a rule, most intractable; whilst in the female they are vagrant and indefinite facts which often aid us in arriviug at a conclusion as to the true nature of the ailment.

Let us ever remember that symptoms apparently hysteroid in character may depend on some organic lesion. We ought therefore to guard against exposing patients unduly to those therapeutic measures so often adopted and found beneficial in the treatment of functional disorders.

CASE.-P. 'T., aged 36, a diamond cutter, presented himself at the National Hospital. Queen Square, on the morning of June 20th. He appeared to be suffering from left hemiplegia; but whilst talking with me, he had several peculiar spasmodic attacks, affecting the left side, to be hereafter described. I admitted him into hospital, under the care of Dr. Ferrier.

Six weeks previously, patient whilst crossing a street got " jammed between two vehicles." He was much frightened, but uninjured, and feeling no special inconvenience, walked on as though nothing had happened. He had not, however, walked far, when, without warning, he fell unconscious on the ground. He was insensible for about tive minutes, but lay perfectly still, there being no convulsive seizure. On regaining conscionsness, patient was unable to walk, having lost power over 
the left leg ; in fact, there was hemiplegia complete of the left side. For four weeks no change was remarked in the condition. Faradic electricity was then applied to the left arm, and thereupon patient had what he calls an attack of "cramp" affecting the whole of the left side; with loss of consciousness.

Patient had always enjoyed good health till five years ago, since which time he had become somewhat timid. This he attributes to his having been detained in a burning building, and having had to drop from one of the windows, a distance of several feet from the ground. His sleep, however, during the last five years had never been specially disturbed, nor had. his health been impaired, as is usual in the subjects of hysteroepilepsy after such accidents.

The fämily history is unimportant, there being no neurosis.

Patient is well-nourished; there is no wasting. He says he is unable to perform any movement with either the left arm or left leg. The left face seems somewhat retracted, the furrows of this side being altogether deeper than those of the right. When, however, all the muscles of the face are called more or less into action, as on exposing the teeth, the right face appears the more active, the left angle of the mouth hanging lower than the right. $\mathrm{He}$ complains of numbness all down the left side of the body, and tactile and painful sensibility. here, compared with the right, is markedly impaired. The superficial reflexes, skin plantar, cremasteric, umbilical, and epigastric, are all well marked. There is no ankle-clonus, nor has there ever been even when sought for immediately after any of his convulsive attacks. There is no special increase of the knee-jerk; the right, however, is apparently greater than the left. There is slight increase in the left wrist tap. The tongue, when protruded, deviates a little to the left. He is unable to letect the difference between salt and sugar when placed on the left half of the tongue, whilst the sensibility of the right is maintained. There is no olfactory anæsthesia, the sense of smell being apparently normal. Patient does not appreciate the tick of the watch with the left ear, neither is the sound conducted and heard in this ear when the watch is applied to the cranium. Both pupils are fairly well dilated; the left, however, is a little larger than the right. 'They react to light and accommodation: when exposed to light, they readily contract, but immediately thereafter dilate again. There is total anæsthesia of the nasal half of the left retina, loss of vision in the left temporal field. There is normal vision with the right eye. Patient occasionally wore a pair of faintly blue-tinted spectacles, and then he often remarked that objects appeared green to the left eye.

The attacks of "cramp" affecting the left side are either 
spontaneous or produced; in whichever way they arise, however, the course and character are always alike. The eyes assume a peculiar stare, and slowly they, with the head, deviate to the left side, the chin resting on the left shoulder. The thenar and hypothenar eminences of the left hand now become approximated, and almost simultaneously with this movement the middle, ring, and little fingers of this same hand are bent in on the palm. He now becomes unconscious. Up to this time he is conscious of all that is going on, and if engriged in conversation, will continue talking. The hand is then slowly but completely pronated, and the arm at the elbow hyper-extended. Sometimes a twitching of the left indexfinger will occur. The left leg is always rigid, but straight. The toes and foot are usually somewhat dorsally flexed, because of an over-action of the muscles governing this movement.

Sometimes in the attacks the whole body would be mure or less markedly affected, patient assuming the position of an arc of a circle, but never, as in true tetanus, did the head and heels form the sole points of rest, other parts of the body always touching the bed. Sometimes the right side of the body would be the seat of contortion, either by itself or in association with the left; when the right alone was affected, the attack had invariably been produced. The attitude of the right differed essentially from that of the left limbs, and here the movements were never so intense as on the left side of the body. When the attack affected the right side alone, whether spontaneous or produced, the first thing to be noted was a twitching of the right index-finger, followed immediately by an approximation of the thenar and hypothenar eminences: but no flexion of the fingers, as in the case of the left, the whole hand assuming rather the shape of a cone. Patient now'would apparently become unconscious, the hand at the same time being supinated, not pronated like the left. The right leg was but rarely affected; when however it was, its state, like that of the left, was straight and rigid. In the attacks patient occasionally bit his tongue, but never urinated.

Immediately before his attacks patient usually complained of "swimming" in the head, feeling as though he should fall to the left; things about him moving to the left also.

The pulse during a seizure invariably numbered about 78 per minute, but fell immediately the attack ceased to 48 ; and continuing thus for some time gradually increased in frequency, till it reached its usual number-varying from 70 to 78 .

The attacks were either spontaneous or produced. There were four distinct hysterogene zones, that is to say, points 
which when pressed upon did in some way or other exert an influence in the production of the "spasms." These spots were situated over the left brachial, left carotid, left femoral and right femoral vessels. It was not, however, necessary to compress in any way these vessels to produce an attack, as simple pinching of the skin at these spots produced the same result. Here there was no apparent increase in the cutaneous sensibility either, and pressure on places markedly more sensitive developed no attack. Compressing the testicle of either side likewise proved worthless.

The cutaneous sensibility in this, as in the majority of cases of hystero-epilepsy, was very variable; but, in testing, I often remarked that immediately $I$ approached any of the above liysterogene points, patient therewith evinced the incipient signs of an attack, which, however, did not become fully developed, if forthwith the excitation were discontinued.

On one occasion; after two spontaneous attacks which followed so closely upon each other as to be hardly separable, and in which both sides of the body were affected, patient remained speechless for two and a half hours, and appeared to experience at the same time difficulty in breathing and swallowing; the diffienlty being more marked with fluids than solids. For many hours after this attack he complained much of a feeling of constriction of the left chest, which did not extend beyond the mid-line.

By applying friction to the furearm during the stage of contracture, but before patient became unconscious, I often succeeded in cutting short an attack.

There was great tenderness in the region of the supra- and infra-orbital nerves, especially the left, yet pressure on these never produced an attack. When the whole body was more or less completely affected by the seizure, the diaphragm invariably participated in the clonic spasm, and the contraction of this muscle would as a rule continue for long after complete relaxation of all the other parts of the body. The diaphragmatic contractions were never accompanied by noise, nor did they ever produce vomiting. If whilst the movements were still continuing in the diaphragm a left-sided attack were indnced, the muscle would maintain a clonic spasm during the time the left side of the body was affected, and would even continue for a few minutes afterwards.

Circulatory troubles are frequent in cases of hystero-epilepsr. Our patient often complained of cardiac palpitation, which at times would be so intense as to produce throbbing in all the vessels of the body, but felt especially in those of the heal and neck. 